\title{
Water-Depth-Based Prediction Formula for the Blasting Vibration Velocity of Lighthouse Caused by Underwater Drilling Blasting
}

\author{
Wenbin Gu, ${ }^{1}$ Zhenxiong Wang, ${ }^{2}$ Jianqing Liu, ${ }^{1}$ Jinglin $\mathrm{Xu},{ }^{1}$ Xin Liu, ${ }^{1}$ and Tao Cao ${ }^{1}$ \\ ${ }^{1}$ PLA University of Science and Technology, Nanjing 210007, China \\ ${ }^{2}$ Unit No. 96863 of PLA, Luoyang 471003, China \\ Correspondence should be addressed to Zhenxiong Wang; wangzhenxiong70310@126.com
}

Received 27 March 2017; Revised 31 May 2017; Accepted 9 July 2017; Published 9 August 2017

Academic Editor: Francesco Pellicano

Copyright ( $\odot 2017$ Wenbin Gu et al. This is an open access article distributed under the Creative Commons Attribution License, which permits unrestricted use, distribution, and reproduction in any medium, provided the original work is properly cited.

Lighthouses are the most important hydraulic structures that should be protected during underwater drilling blasting. Thus, the effect of blasting vibration on lighthouse should be studied. On the basis of the dimensional analysis, we deduced a revised formula for water depth based on Sodev's empirical formula and established the linear fitting model. During the underwater reef project in the main channel of Shipu Harbor in the Ningbo-Zhoushan Port, the blasting vibration data of the lighthouse near the underwater blasting area were monitored. The undetermined coefficient, resolvable coefficient, and $F$ value of the two formulas were then obtained. The comparison of the data obtained from the two formulas showed that they can effectively predict the blasting vibration on the lighthouse. The correction formula that considers water depth can obviously reduce prediction errors and accurately predict blasting vibration.

\section{Introduction}

With the rapid development of the national economy, developing and utilizing marine and river resources had become increasingly urgent. The construction of port terminals and water power facilities and the laying of oil pipelines require extensive excavation of underwater rock formations. Underwater drilling blasting can maximize the explosiveness of the force and energy of broken rocks through the blasting effect. The unit consumption of explosives and the shock impact are small; hence, underwater drilling blasting has become the main method of modern underwater blasting [1-3]. As an important branch of engineering blasting, such method plays an increasingly important role in the national defense infrastructure and the national economy. Moreover, its applications have expanded, and the research on the damage effect of underwater drilling blasting has become increasingly valuable [4]. Underwater drilling blasting exerts a very strong destructive effect on buildings near the water area. The main hazards include the blasting seismic effect, shock wave and bubble pressure, air shock wave, and blasting fly rock and swell. The blasting seismic and water shock wave effects are the most serious. In these cases, the explosive energy of underwater drilling blasting is consumed by the rock damage, compression, and movement. The seismic effect of underwater blasting is first transmitted through the water and the rock mass and then spreads to the nearest building and land. The damaging effect of the blasting vibration on hydraulic structures near the explosion area is much greater than that of the shock wave in the water [5-7].

Lighthouses are the most common hydraulic constructions affected within underwater drilling blasting areas. The distance between a lighthouse and a blasting area is usually very small. Thus, the effect on blasting vibration on lighthouses must be investigated. The blasting vibration of lighthouses should be controlled within a reasonable and safe range [8-10]. The blasting vibration prediction from the reasonably acquired blasting vibration data can be used as a reference for blasting vibration hazard control under similar construction conditions. 
The blasting vibration attenuation law based on site conditions is an important basis for the design and prediction of engineering blasting. This concept is also the key issue to address in the study of the effect of blasting on adjacent buildings. Saadat et al. attempt to reveal the differential evolution algorithm for predicting blast induced ground vibrations by contrast and analysis. Square and cubic root scaled distance predictors are the best among other empirical models [11]. This law is commonly described by the former Soviet M. A. Sodev's empirical formula (cubic root scaled distance predictors):

$$
v=k\left(\frac{\sqrt[3]{Q}}{R}\right)^{\alpha}
$$

where $v$ is the blasting vibration velocity; $Q$ is the quantity of explosive charge used per delay; $R$ is the distance $(\mathrm{m})$ between the observation and blast points; $k$ and $\alpha$ are site-specific constants, which are estimated by the regression analysis of the observed data obtained by recording several experimental blasts with different charge weights at various distances.

On the basis of the data from the small-scale blasting and field tests, this method can be used to compute the undetermined coefficients $k$ and $\alpha$, which are related to the blasting method, geology, and topography conditions in certain areas and blasting forms. Sodev's empirical formula has been demonstrated by most engineering tests and is widely used because of the high accuracy of the predicted particle velocity of blasting vibrations at ground level, under flat terrain conditions [12-15]. The accuracy of this formula is poor when the blasting environment is complex and the topography of the blasting site changes greatly. In the literature [16-20], the elevation difference between the measuring point and the blasting area is taken as the influencing factor. Based on the dimension analysis, the revised formula, which considers the height difference, is deduced from Sodev's empirical formula and has improved prediction accuracy. In addition to the empirical formula method, many researchers have employed the BP neural network to predict the blasting vibration intensity and obtain a better prediction results [21-23]. However, empirical formula method can intuitively express the influence of bursting distance, charge, and other factors on vibration intensity and can be used efficiently in engineering. Therefore, the study was based on the formula method.

Compared with land blasting, underwater borehole blasting must consider the factors that are highly influenced by the presence of water. Similar to the height effect considered for the prediction of land blasting, the effect of water depth on the prediction of the blasting vibration of underwater boreholes should also be considered [24]. Therefore, the influence of water depth must be considered for the prediction of underwater drilling blasting vibration.

On the basis of the dimensional analysis, we deduced the formula for blasting vibration prediction considering the water-depth effect. During the underwater reef project of the main channel of the Shipu Harbor in the Ningbo-Zhoushan Port, the vibration data of the measured points at the lighthouse near the blasting area under different water depths, the charge amount, and the burst distance were obtained. The prediction accuracies of Sodev's empirical formula and the revised formula, which considers the water depth, were compared and analyzed. The comparison results could serve as a reference for the prediction method for controlled blasting under complex condition.

\section{Revised Water-Depth-Based Prediction Formula for Blasting Vibration in Underwater Drilling Blasting}

The blasting vibration of a lighthouse is affected by the explosion source, medium conditions (such as rock properties and joint and geological structures), water depth, the distance between the measuring point and the blasting area, and the height difference. Ten major physical quantities are involved in the propagation of seismic waves (Table 1). According to the $\pi$ theorem, the particle peak vibration velocity in the lighthouse can be expressed as

$$
V=\Phi(Q, R, c, \rho, H, h, L, F, v, t) \text {. }
$$

In Table $1, L, T$, and $M$ represent the length, time, and mass dimensions, respectively.

On the basis of the $\pi$ theorem, we selected $Q, R$, and $c$ as the independent variables, and $\pi$ represents the dimensionless quantity [1]:

$$
\pi=\frac{V}{Q^{\chi_{1}} R^{\chi_{2}} C^{\chi_{3}}}
$$

where $\chi_{1}, \chi_{2}$, and $\chi_{3}$ are undetermined coefficients. In the dimensionless homogeneous theorem, the molecular and denominator dimensions are consistent. Thus,

$$
\operatorname{dim} v=L T^{-1}=(M)^{\chi_{1}}(L)^{\chi_{2}}\left(L T^{-1}\right)^{\chi_{3}} .
$$

When $\chi_{1}=0, \chi_{2}=0$, and $\chi_{3}=1$, we obtain

$$
\pi=\frac{V}{c} .
$$

The remaining physical quantities can be expressed as

$$
\begin{aligned}
& \pi_{1}=\frac{\rho}{Q R^{-3}}, \\
& \pi_{2}=\frac{H}{R}, \\
& \pi_{3}=\frac{h}{R}, \\
& \pi_{4}=\frac{L}{R}, \\
& \pi_{5}=\frac{F}{R^{-1} c}, \\
& \pi_{6}=\frac{t}{R c^{-1}} .
\end{aligned}
$$


TABLE 1: Major physical parameters.

\begin{tabular}{|c|c|c|c|c|}
\hline & Number & Symbol & Name & Dimension \\
\hline \multirow{7}{*}{ Independent variable } & 1 & Q & Charge amount & $M$ \\
\hline & 2 & $R$ & Distance between the measuring point and the blasting area & $L$ \\
\hline & 3 & C & Seismic wave velocity & $L T^{-1}$ \\
\hline & 4 & $P$ & Rock-medium density in water & $M L^{-3}$ \\
\hline & 5 & $H$ & Height difference between the measuring point and the blasting area & $L$ \\
\hline & 6 & $h$ & Depth of the blasting area & $L$ \\
\hline & 7 & $L$ & Hole depth & $L$ \\
\hline \multirow{3}{*}{ Dependent variable } & 8 & $F$ & Particle vibration frequency & $T^{-1}$ \\
\hline & 9 & $V$ & Peak particle vibration velocity & $L T^{-1}$ \\
\hline & 10 & $T$ & Duration & $T$ \\
\hline
\end{tabular}

Equations (2), (5), and (6) are combined as follows:

$$
\pi=\frac{V}{c}=\Phi\left(\frac{\rho}{Q R^{-3}}, \frac{H}{R}, \frac{h}{R}, \frac{L}{R}, \frac{F}{R^{-1} c}, \frac{t}{R c^{-1}}\right) .
$$

The amount of multiplication of two different dimensionless quantities is still dimensionless $[25,26]$. Therefore, the combination of $\pi_{1}$ and $\pi_{3}$ yields a new dimensionless quantity $\pi_{7}$ as follows:

$$
\pi_{7}=\left(\pi_{1}\right)^{1 / 3} \pi_{3}=\left(\frac{\rho}{Q R^{-3}}\right)^{1 / 3}\left(\frac{h}{R}\right) .
$$

Equations (7) and (8) show that $V / c$ and $\left(\rho / Q R^{-3}\right)^{1 / 3}(h / R)$ have a certain functional relationship. Under the same test site conditions, the rock density $\rho$ and seismic wave velocity $c$ can be considered constant. Thus,

$$
\ln V=\alpha_{1}+\beta_{1} \ln \left(\frac{\sqrt[3]{Q}}{R}\right)-\left[-\alpha_{2}+\beta_{2} \ln \left(\frac{h}{R}\right)\right] .
$$

The blasting vibration produced by land blasting is usually predicted by Sodev's empirical formula:

$$
v=k\left(\frac{\sqrt[3]{Q}}{R}\right)^{\alpha}
$$

where $v$ is the vibration velocity of a given point, $k$ and $\alpha$ are the parameters that describe the propagating media and monitoring points.

The logarithm of both sides of (10) is

$$
\ln v=\ln k+\alpha\left(\frac{1}{3} \ln Q-\ln R\right) .
$$

We let $\ln v=\ln v_{0}, \ln k=\alpha_{1}$, and $\alpha=\beta_{1}$. Hence,

$$
\ln v=\alpha_{1}+\beta_{1}\left(\frac{1}{3} \ln Q-\ln R\right) \text {. }
$$

By substituting (12) into (9), we obtain

$$
\begin{aligned}
\ln V & =\ln v_{0}-\left[-\alpha_{2}+\beta_{2} \ln \left(\frac{h}{R}\right)\right] \\
& =\ln v_{0}+\alpha_{2}-\beta_{2}\left(\frac{h}{R}\right) \\
& =\ln k_{1}\left(\frac{\sqrt[3]{Q}}{R}\right)^{\beta_{1}}+\alpha_{2}-\beta_{2} \ln \left(\frac{h}{R}\right) .
\end{aligned}
$$

We let $\ln k_{2}=\alpha_{2}, \gamma=-\beta_{2}$. Then,

$$
V=k_{1} k_{2}\left(\frac{\sqrt[3]{\mathrm{Q}}}{R}\right)^{\beta_{1}}\left(\frac{h}{R}\right)^{\gamma}=K\left(\frac{\sqrt[3]{\mathrm{Q}}}{R}\right)^{\beta_{1}}\left(\frac{h}{R}\right)^{\gamma},
$$

where $k_{1}$ is the influence coefficient of the site of the seismic wave propagation area, $k_{2}$ is the influence coefficient of the water environment, $K$ is the influence coefficient that considers the length and the water environment, $\beta_{1}$ is the attenuation coefficient the reflects the influence of the charge quantity, and $\gamma$ is the attenuation coefficient that reflects the influence of water depth. The other symbols are the same as those mentioned above.

\section{Fitting Model}

Equation (14) shows that dependent variable $V$ is not linearly related to charge $Q$, burst center distance $R$, and water depth $h$. To facilitate the calculation, proportional dose $\rho_{Q}$ and proportion of water depth $\rho_{h}$ are introduced. Then,

$$
V=K\left(\frac{\sqrt[3]{\mathrm{Q}}}{R}\right)^{\beta_{1}}\left(\frac{h}{R}\right)^{\gamma}=K \rho_{\mathrm{Q}}^{\beta_{1}} \rho_{h}^{\gamma} .
$$

By taking the logarithms of both sides of the equation, we obtain

$$
\ln V=\ln K+\beta_{1} \ln \rho_{\mathrm{Q}}+\gamma \ln \rho_{h} .
$$

For further calculation, we let $\ln V=y, a_{1}=\beta_{1}, x_{1}=$ $\ln \rho_{Q}, a_{2}=\gamma$, and $x_{2}=\ln \rho_{h} . b_{0}$ is introduced as an additional coefficient. Accordingly, (16) can be rewritten as a linear homogeneous equation as follows:

$$
y=a_{0}+a_{1} x_{1}+a_{2} x_{2}+b_{0} .
$$

According to the number of experiments, the linear equations can be obtained by fitting the following vibration data:

$$
\begin{gathered}
y_{1}=a_{0}+a_{1} x_{11}+a_{2} x_{12}+b_{1} \\
y_{2}=a_{0}+a_{1} x_{21}+a_{2} x_{22}+b_{2} \\
\vdots \\
y_{n}=a_{0}+a_{1} x_{n 1}+a_{2} x_{n 2}+b_{n},
\end{gathered}
$$


where $y_{1} \cdots y_{n}$ are the index of vibration velocity data; $x_{11} \cdots x_{n 1}$ are the index of proportional dose $\rho_{Q} ; x_{21} \cdots x_{n 2}$ are the index the proportion of water depth $\rho_{h} ; b_{1} \cdots b_{n}$ are introduced as an additional coefficient.

The above equation is transformed into a matrix equation:

$$
\begin{aligned}
& Y=X A+B \\
& B \sim N\left(0, \sigma^{2} I_{n}\right),
\end{aligned}
$$

where

$$
\begin{aligned}
Y & =\left(\begin{array}{c}
y_{1} \\
y_{2} \\
\vdots \\
y_{n}
\end{array}\right), \\
X & =\left(\begin{array}{ll}
x_{11} & x_{12} \\
x_{21} & x_{22} \\
& \ldots \\
x_{n 1} & \\
a_{n 2}
\end{array}\right), \\
A & =\left(\begin{array}{c}
a_{0} \\
a_{1} \\
a_{2} \\
b_{1} \\
b_{2} \\
\vdots \\
b_{n}
\end{array}\right),
\end{aligned}
$$

According to the principle of least-squares estimation, the problem is transformed into a problem of solving the minimum.

$$
Q_{e}=Y-X \widehat{A}-\widehat{B}
$$

where $\widehat{A}$ and $\widehat{B}$ are the best estimated values of $A$ and $B ; Q_{e}$ is the minimum that can be achieved. The partial derivative of the above equation can be obtained as follows:

$$
\begin{aligned}
& \left.\frac{\partial Q_{e}^{2}}{\partial A}\right|_{A=\widehat{A}}=-2 X^{\prime}(Y-X \widehat{A}-\widehat{B})=0 \\
& \left.\frac{\partial Q_{e}^{2}}{\partial B}\right|_{B=\widehat{B}}=-2(Y-X \widehat{A}-\widehat{B})=0,
\end{aligned}
$$

where $X^{\prime}$ is the transpose of $X$. That is, matrix equation

$$
X^{\prime}(Y-X \widehat{A})=0 .
$$

If $X$ is a column full rank, the least-squares estimate of $A$ is

$$
\widehat{A}=\left(X^{\prime} X\right)^{-1}\left(X^{\prime} Y\right)=\left(\begin{array}{c}
\widehat{a_{0}} \\
\widehat{a_{1}} \\
\widehat{a_{2}}
\end{array}\right) \text {. }
$$

The linear fitting model of the vibration velocity formula considers the water depth by replacing the variables of the above parameters as shown below:

$$
V=e^{\widehat{a_{0}}}\left(\frac{\sqrt[3]{Q}}{R}\right)^{\widehat{\beta_{1}}}\left(\frac{h}{R}\right)^{\widehat{\gamma}}
$$

where $K=e^{\widehat{a_{0}}}, \beta_{1}=\widehat{\beta_{1}}$, and $\gamma=\widehat{\gamma}$.

The fitting value is not true because of the difference in data. The calculation model was tested and evaluated using the coefficient of determination $(\mathrm{CoD})$ and the significance test ( $F$ test) [27].

As an important indicator of model quality, $\mathrm{CoD}$ can measure the close relationship between the independent and dependent variables. The independent variable explains the percentage change of the dependent variable. Larger values result in better models. The formula is

$$
\mathrm{CoD}=\left[\frac{\sum(x-\bar{x})(y-\bar{y})}{\sqrt{\sum(x-\bar{x})^{2}} \sqrt{(y-\bar{y})^{2}}}\right]^{2} .
$$

$F$-test calculation formula:

$$
F=\frac{\sum(y-\bar{y})^{2}}{m s^{2}}=\frac{\operatorname{CoD}(n-2)}{m(1-\mathrm{CoD})},
$$

where $\bar{x}$ and $\bar{y}$ are the arithmetic mean of $x$ and $y ; n$ is the number of samples; $m$ is the number of independent variables; and $s$ is the standard error, which is the average square error between the regression line and the dependent variable. It is a measure of the deviation of the dependent variable from the regression line. The formula is as follows:

$$
s=\sqrt{\frac{\sum(y-\bar{y})^{2}}{n-m-1}} .
$$

$F$ can be used to test whether a significant linear statistical relationship exists between the overall effects of the independent and dependent variables; that is, whether the linear relationship between the dependent and independent variables is significant. In theory, a higher $F$ value signifies a higher fitting accuracy.

\section{Project Examples}

Shipu Harbor is a comprehensive harbor that integrates passenger and cargo transport, the port industry, marine fishery, and tourism. The Shipu port conditions are desirable, but the channel is in the natural state. Hence, adapting to the trend of large-scale ships is difficult. By constructing the Shipu port channel, upgrading the existing channel, and building a 10,000-ton channel, the optimal allocation of harbor resources can be achieved. Many underwater reefs are required during the expansion of the main channel, and a lighthouse in the blasting area needs to be demolished. The project (as shown in Figure 1) provides a test platform that can closely monitor the effects of blasting vibration on near-site 


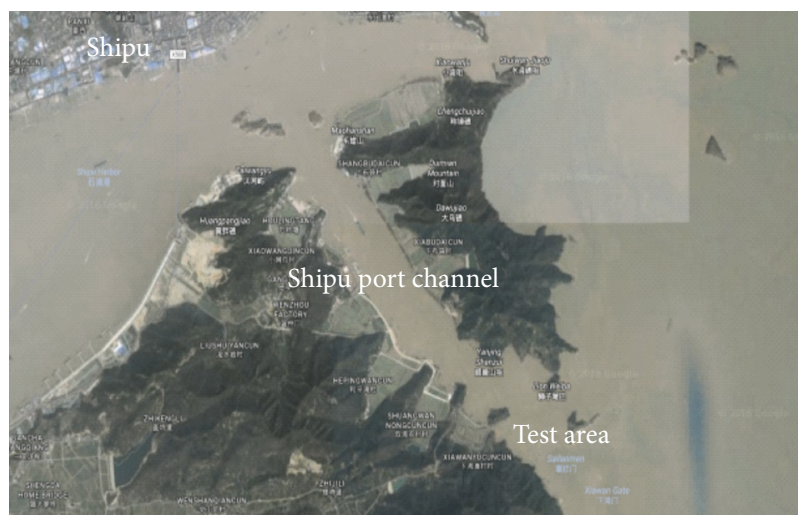

Figure 1: Project location.

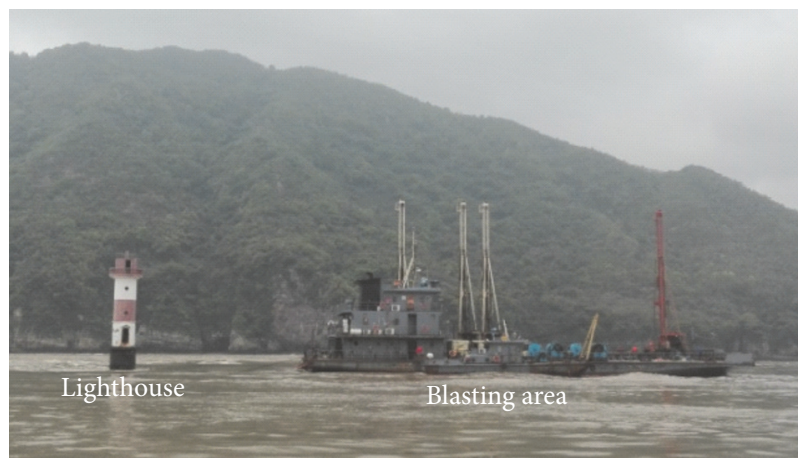

FIGURE 2: Lighthouse and blasting area site map.

hydraulic structures. The relative locations of the lighthouse and the blasting area are shown in Figure 2, and the blasting area is located below the working platform.

As the lighthouse is located in the blasting area, the lighthouse is demolished at the end of the construction, and no target building needs to be protected within $300 \mathrm{~m}$ of the blasting area. Therefore, the blasting network uses all blasting holes simultaneously. According to the tide table, the researchers boarded the lighthouse in Figure 2 with a traffic boat under safety condition. In the middle of the lighthouse, the TC- 4850 vibration tester is set up. The $x$ direction of the vibration sensor points to the burst area, and the $y$ direction is perpendicular to the explosion area. The settings are shown in Figure 3. The depth of the lighthouse changes with the tides. The traffic boat can be docked in the lighthouse only at the right time, and the researchers are to complete the vibration tester settings. Thus, the vibration sensor is maintained in the data-acquisition state to ensure that the vibration data can be collected when blasting. The vibration tester can be operated continuously for 50 hours and then taken back for charging. After charging, the vibration data is derived and then placed in the lighthouse. Figure 4 shows the underwater drilling blasting.

The blasting network used in the experiment is all holes blasted at the same time, so the detonation dose is the total charge in the fitting formula. The diameter of the hole is $90 \mathrm{~mm}$; the charge diameter is $70 \mathrm{~mm}$. The number of holes,

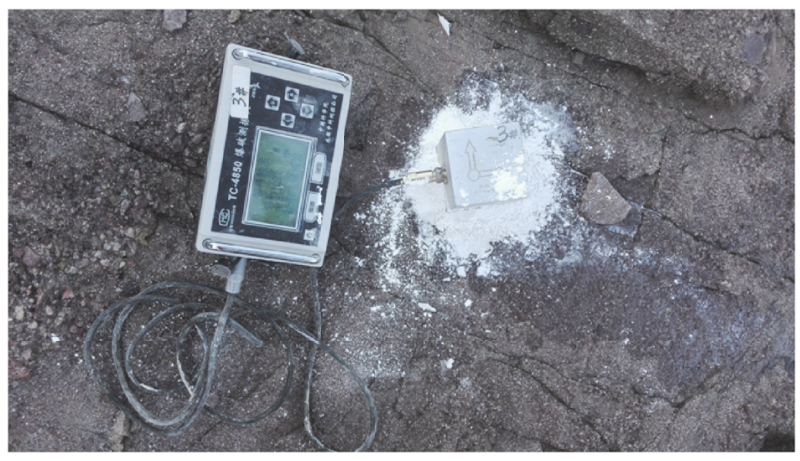

Figure 3: Vibration tester (TC-4850).

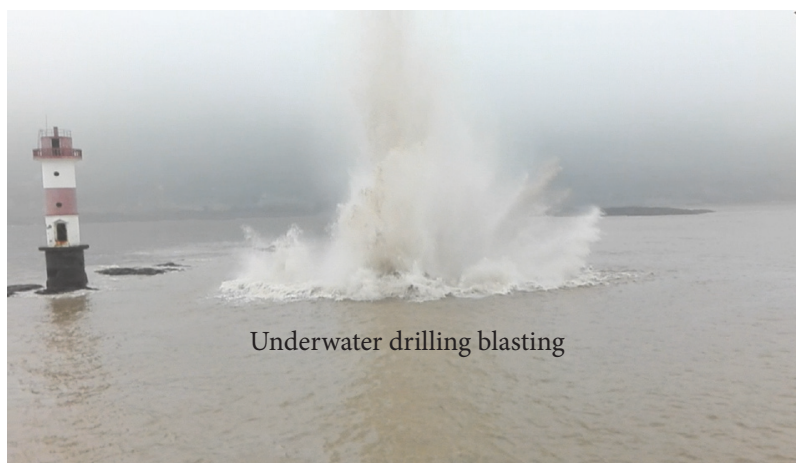

FIGURE 4: Scene of underwater drilling blasting.

the quality of the explosive, the depth of the water, the distance of each explosion center, the data of the monitored vibration velocity, and other specific data are listed in Table 2.

Vertical vibration velocity is widely accepted as an evaluation criterion in engineering blasting [28, 29]. However, it ignores the impact of horizontal tangential and radial vibrations and only considers the vertical direction of vibration velocity. Using the higher peak particle velocity in the horizontal and vertical directions as the highest vibration intensity evaluation standard is of great reference value. However, using the vibration velocity as the evaluation criterion in a specific or certain direction cannot reflect the vibration intensity of the measured point comprehensively. Therefore, the vector summation of the three-direction vibration velocity data can be used to reflect the change rule of the vibration of the measuring point during blasting. Adopting the peak vibration velocity vector (PVV) to predict the vibration intensity is reasonable.

$$
\operatorname{PVV}=\sqrt{\left(v_{x-t}\right)^{2}+\left(v_{y-t}\right)^{2}+\left(v_{z-t}\right)^{2}},
$$

where $v_{x-t}, v_{y-t}$, and $v_{z-t}$ represent the particle vibration velocity in the $x, y$, and $z$ directions, respectively.

In [12], the square sum of peak velocity (SPV) in three directions is adopted as the index for predicting and analyzing the blasting vibration intensity. SPV values are usually greater than PVV because the three directions of vibration velocity do not necessarily reach the peak simultaneously. 
TABLE 2: Vibration data.

\begin{tabular}{|c|c|c|c|c|c|c|c|c|c|}
\hline Serial number & Number of holes & $\begin{array}{l}Q \\
\mathrm{~kg}\end{array}$ & $\begin{array}{l}h \\
\mathrm{~m}\end{array}$ & $\begin{array}{l}R \\
\mathrm{~m}\end{array}$ & $\begin{array}{l}v_{x-\max } \\
\mathrm{cm} / \mathrm{s}\end{array}$ & $\begin{array}{l}v_{y-\max } \\
\mathrm{cm} / \mathrm{s}\end{array}$ & $\begin{array}{l}v_{z-\max } \\
\mathrm{cm} / \mathrm{s}\end{array}$ & $\begin{array}{l}\mathrm{PVV} \\
\mathrm{cm} / \mathrm{s}\end{array}$ & $\begin{array}{l}\mathrm{SPV} \\
\mathrm{cm} / \mathrm{s}\end{array}$ \\
\hline 1 & 31 & 513 & 12.96 & 54.36 & 4.494 & 15.039 & 10.705 & 15.127 & 18.999 \\
\hline 2 & 20 & 450 & 9.97 & 50.51 & 8.093 & 8.908 & 7.229 & 11.282 & 14.039 \\
\hline 3 & 22 & 588 & 11.59 & 47.20 & 7.523 & 16.996 & 13.144 & 17.029 & 22.765 \\
\hline 4 & 30 & 1008 & 8.44 & 45.15 & 19.546 & 7.656 & 15.106 & 20.934 & 25.862 \\
\hline 5 & 29 & 1122 & 7.59 & 43.06 & 17.214 & 16.179 & 18.078 & 28.179 & 29.747 \\
\hline 6 & 30 & 1132 & 7.36 & 42.27 & 18.415 & 19.062 & 16.841 & 29.102 & 31.402 \\
\hline 7 & 29 & 916 & 8.90 & 39.60 & 16.852 & 16.184 & 15.519 & 27.009 & 28.049 \\
\hline 8 & 46 & 1353 & 9.07 & 39.61 & 15.389 & 16.705 & 18.217 & 28.408 & 29.116 \\
\hline 9 & 30 & 597 & 9.98 & 43.48 & 18.78 & 18.297 & 12.768 & 22.587 & 29.163 \\
\hline 10 & 48 & 1635 & 10.09 & 45.90 & 16.874 & 21.099 & 14.791 & 24.829 & 30.800 \\
\hline 11 & 48 & 2112 & 8.20 & 50.41 & 19.783 & 23.489 & 25.691 & 35.429 & 40.039 \\
\hline 12 & 48 & 1615 & 4.96 & 53.54 & 6.724 & 10.763 & 10.563 & 12.393 & 16.512 \\
\hline
\end{tabular}

TABLE 3: Table of coefficients fitted using (10).

\begin{tabular}{lccccc}
\hline & $v_{x-\max }$ & $v_{y-\max }$ & $v_{z-\max }$ & PVV & SPV \\
\hline$k$ & 193.64 & 31.125 & 99.286 & 269.616 & 116.863 \\
$\alpha$ & 1.742 & 0.426 & 1.245 & 1.589 & 0.978 \\
CoD & 0.490 & 0.079 & 0.633 & 0.629 & 0.653 \\
$F$ & 14.429 & 1.718 & 21.205 & 15.276 & 14.320 \\
\hline
\end{tabular}

From the safety perspective, SPV amplifies the predicted value of vibration intensity but can control the blasting vibration intensity strictly. Employing SPV is suitable for predicting the vibration intensity.

$$
\mathrm{SPV}=\sqrt{\left(v_{x-\max }\right)^{2}+\left(v_{y-\max }\right)^{2}+\left(v_{z-\max }\right)^{2}},
$$

where $v_{x \text {-max }}, v_{y \text {-max }}$, and $v_{z \text {-max }}$ represent the particle peak velocities in the $x, y$, and $z$ directions, respectively. Using (10) and (14) to fit the vibration data, we fitted the coefficient table as shown in Table 3.

Regardless of which formula is used the resolvable coefficients in the $x$ and $y$ directions are small, especially in the $y$ direction using Sodev's empirical formula. The vibration data of these two directions are scattered, and the formula cannot accurately reflect the law. However, the two formulas are suitable for predicting the vibration data of $v_{z \text {-max }}, \mathrm{PVV}$, and SPV. The CoD of the revised formula calculation model is larger than Sodev's empirical formula, as shown in Figure 5. The revised formula improves the fitting accuracy and can reflect the relationship between the vibration data and the dependent variable more effectively than Sodev's empirical formula. The results of the significance test are consistent compared to the results of the resolvable coefficients. The revised formula improves $F$ and increases the prediction accuracy, as shown in Figure 6.

Normally, the distance between the measuring point and the explosive area is greater than the water depth; that is, the proportion of water depth is less than 1 . In Table 4, the fitted depth attenuation index $\gamma<1$ indicates that the vibration

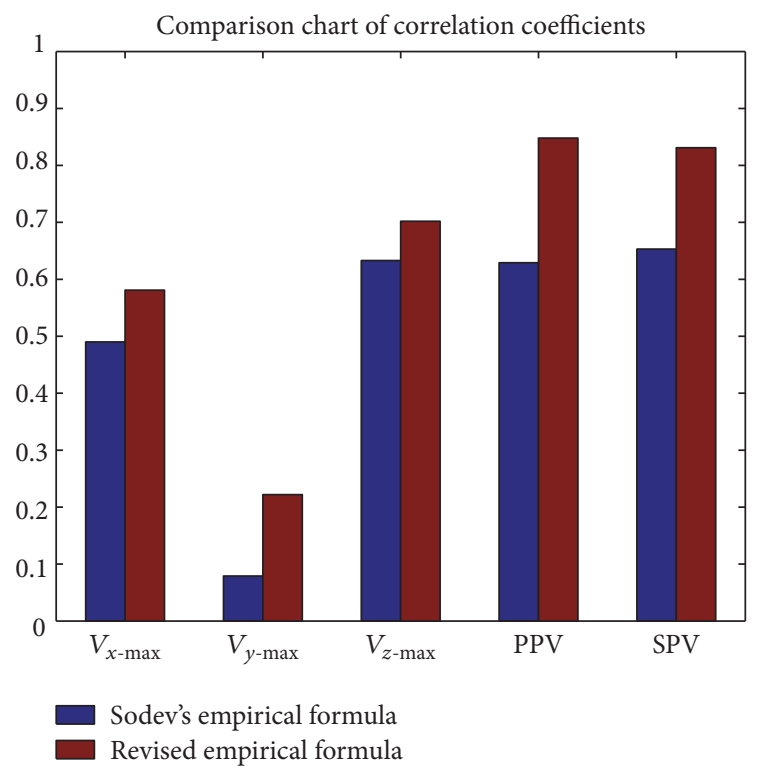

FIGURE 5: Comparison chart of coefficients.

TABle 4: Table of coefficients fitted using (14).

\begin{tabular}{lccccc}
\hline & $v_{x-\max }$ & $v_{y-\max }$ & $v_{z-\max }$ & PVV & SPV \\
\hline$K$ & 746.205 & 95.393 & 207.680 & 695.061 & 350.724 \\
$\beta_{1}$ & 1.966 & 0.649 & 1.367 & 1.559 & 1.161 \\
$\gamma$ & 0.606 & 0.503 & 0.332 & 0.633 & 0.494 \\
CoD & 0.581 & 0.222 & 0.702 & 0.848 & 0.831 \\
$F$ & 12.124 & 1.879 & 18.072 & 18.747 & 19.270 \\
\hline
\end{tabular}

velocity increases with the water depth at the same charge and explosive distance. The water cover influences the throwing effect because of the enhanced effect of underwater clogging; when the explosives detonate in the underwater rock, a part of the throwing energy is converted to blasting energy [30]. Therefore, the seismic effect of underwater blasting is greater 
TABLE 5: Comparison between the calculated value and the measured value.

\begin{tabular}{|c|c|c|c|c|c|c|c|c|c|c|}
\hline \multirow[t]{2}{*}{ Number } & \multicolumn{2}{|c|}{$v_{x-\max }$} & \multicolumn{2}{|c|}{$v_{y \text {-max }}$} & \multicolumn{2}{|c|}{$v_{z \text {-max }}$} & \multicolumn{2}{|c|}{ PVV } & \multicolumn{2}{|c|}{ SPV } \\
\hline & Eq. (10) & Eq. (14) & Eq. (10) & Eq. (14) & Eq. (10) & Eq. (14) & Eq. (10) & Eq. (14) & Eq. (10) & Eq. (14) \\
\hline 1 & 0.532 & 0.612 & 0.085 & 0.110 & 0.146 & 0.121 & 0.151 & 0.064 & 0.055 & 0.016 \\
\hline 2 & 0.104 & 0.153 & 0.565 & 0.393 & 0.313 & 0.273 & 0.194 & 0.167 & 0.317 & 0.255 \\
\hline 3 & 0.267 & 0.415 & 0.123 & 0.098 & 0.122 & 0.067 & 0.015 & 0.133 & 0.053 & 0.035 \\
\hline 4 & 0.280 & 0.283 & 1.142 & 1.019 & 0.010 & 0.007 & 0.179 & 0.100 & 0.037 & 0.032 \\
\hline 5 & 0.055 & 0.074 & 0.050 & 0.021 & 0.064 & 0.075 & 0.000 & 0.104 & 0.022 & 0.040 \\
\hline 6 & 0.083 & 0.104 & 0.101 & 0.451 & 0.031 & 0.018 & 0.001 & 0.110 & 0.054 & 0.073 \\
\hline 7 & 0.007 & 0.131 & 0.057 & 0.309 & 0.112 & 0.194 & 0.070 & 0.118 & 0.054 & 0.170 \\
\hline 8 & 0.364 & 0.020 & 0.082 & 0.189 & 0.114 & 0.222 & 0.250 & 0.217 & 0.153 & 0.071 \\
\hline 9 & 0.409 & 0.354 & 0.155 & 0.143 & 0.007 & 0.058 & 0.121 & 0.062 & 0.195 & 0.136 \\
\hline 10 & 0.380 & 0.344 & 0.277 & 0.289 & 0.166 & 0.140 & 0.242 & 0.212 & 0.263 & 0.230 \\
\hline 11 & 0.097 & 0.148 & 0.260 & 0.330 & 0.297 & 0.319 & 0.135 & 0.264 & 0.234 & 0.271 \\
\hline 12 & 1.046 & 0.327 & 0.515 & 0.000 & 0.420 & 0.120 & 0.949 & 0.167 & 0.603 & 0.125 \\
\hline Mean & 0.302 & 0.247 & 0.284 & 0.279 & 0.150 & 0.134 & 0.192 & 0.142 & 0.170 & 0.121 \\
\hline
\end{tabular}

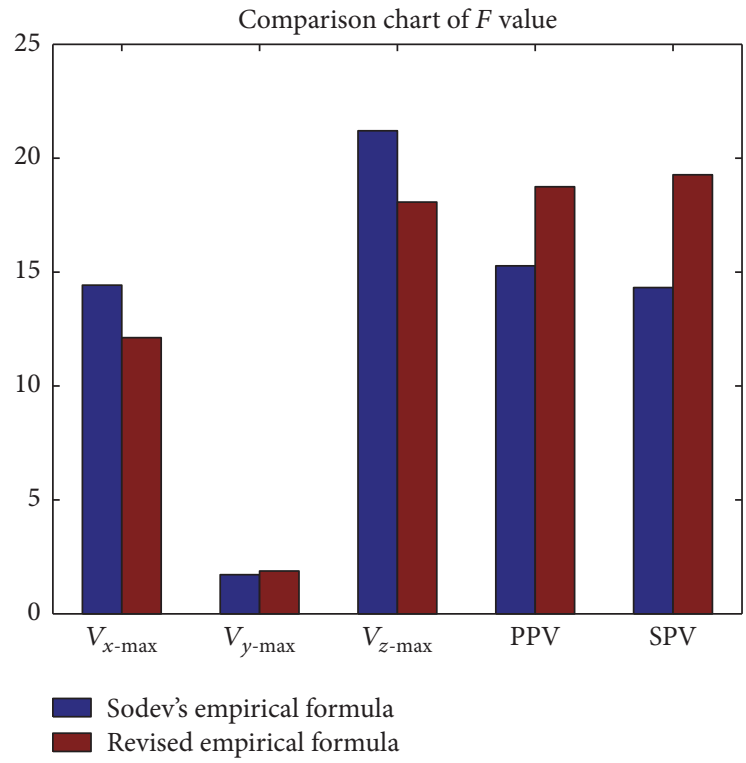

Figure 6: Comparison chart of the $F$ value.

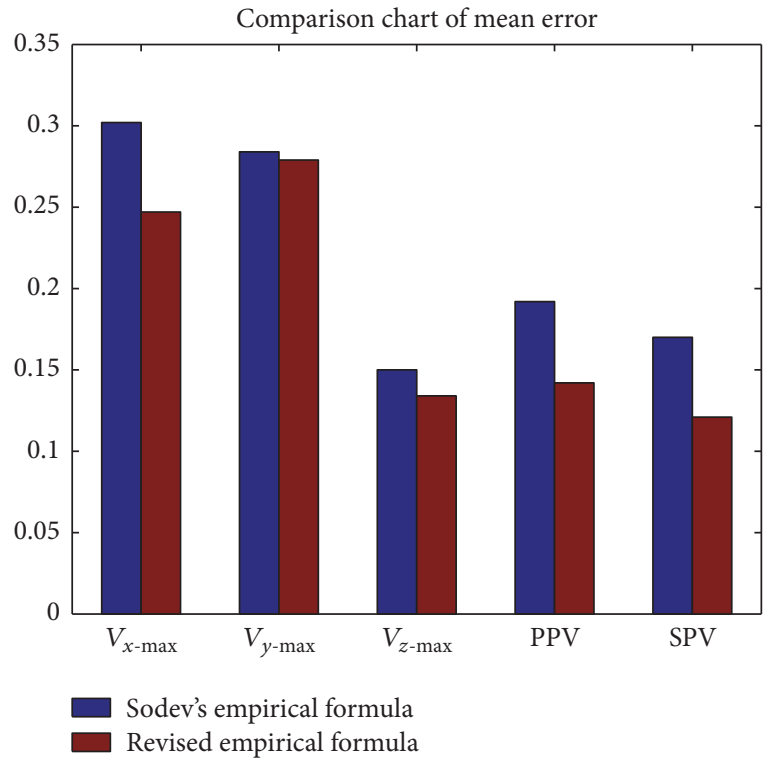

FIgURE 7: Comparison of mean error. than that of the same grade of land and rock blasting. The total energy percentage of the blasting vibration energy of underwater drilling blasting should be more than that of the general land-rock blasting vibration energy [2]. Explosive energy is increasingly used to form stress waves because of the influence of water pressure. Water depth is the most important factor that influences the seismic wave intensity of underwater drilling blasting. The water pressure of the blasting area varies with the water depths, and the influence of blasting-energy distribution also differs.

The average error of the predicted data of $v_{z \text {-max }}, \mathrm{PVV}$, and SPV is less than $20 \%$ of the measured data, as shown in Figure 7 and Table 5, which is because of the smaller detonation distance range and vibration data discretization. This observation implies that the formula can effectively predict the blasting vibration intensity. The error comparison chart shows that the error of the revised formula based on water depth is smaller than that of Sodev's empirical formula.

\section{Conclusions}

The seismic effect of underwater drilling blasting is a complex problem. The special effects of water media on blasting earthquakes should be taken into account. The law of attenuation of seismic waves on land cannot be used.

(1) Water depth is an important factor that affects the vibration intensity of underwater drilling blasting. The revised blasting vibration formula that considers water depth was deduced and analyzed through dimensional analysis. 
(2) Blasting vibration data under different conditions were obtained by monitoring the lighthouse vibration near the blasting area. $v_{z \text {-max }}, \mathrm{PVV}$, and SPV can be used as predictors of blasting vibration intensity. Among the predictors, PVV is the most comprehensive, and SPV has the highest safety factor.

(3) The blasting vibration data can be predicted by Sodev's empirical formula and the modified Sodev's empirical formula. By comparing the predicted value with the measured value, the prediction error of the two formulas was within $20 \%$. Therefore, these two formulas can be used to predict the vibration intensity of the lighthouse near the underwater drilling blasting area, and the modified Sodev's empirical formula considering the water depth can improve the prediction accuracy.

\section{Conflicts of Interest}

The authors declare that there are no conflicts of interest regarding the publication of this paper.

\section{Acknowledgments}

This work was supported by a Grant from National Defense Program, no. BY209J033.

\section{References}

[1] X. W. Chai, Propagation Characteristics of Shock Wave in Underwater Blasthole Blasting, Wuhan University of Technology, Wuhan, China, 2009.

[2] X. Q. Liang, Underwater blasting technology, Chemical Industry Press, Beijing, China, 2013.

[3] V. M. Tavrizov, "Experience in drilling and blasting operations to Loosen underwater rocks," Hydrotechnical Construction, vol. 17, no. 11, pp. 597-604, 1983.

[4] G. Tripathy and R. Shirke, "Underwater drilling and blasting for hard rock dredging in indian ports - a case study," Aquatic Procedia, vol. 4, pp. 248-255, 2015.

[5] J. Liang, "Implementation and monitoring of shock absorption measures for close hydraulic structures," Zhujiang River water transport, vol. 9, p. 3840, 2007.

[6] C. J. Chen, L. Wu, J. W. Zhao, B. Li, H. y. Li, and C. J. Li, "Influence of underwater drilling and blasting on adjacent structure safety," Blasting, vol. 33, no. 2, pp. 117-122, 2016.

[7] Huo Y., "Effect of blasting vibration on hydraulic structures and safety analysis," Engineering Blasting, vol. 9, no. 4, pp. 72-77, 2003.

[8] Y. Su, L. Wu, Y. X. Peng, R. F. Zhou, and X. M. Su, Research review on safety criterion of underwater blasting nearby constructions. explosive materials, vol. 45, no. 3, pp. 55-61, 2016.

[9] G. N. Liu, L. S. Tang, Y. L. Qi, and H. T. Sang, “Test and analyses of the effect of underwater controlled blasting project in complex environment," China Earthquake Engineering Journal, vol. 37, no. 3, pp. 1037-1041, 2015.

[10] A. J. Moore, A. B. Richards, and E. Gad, "Structural response of brickveneer houses to blast vibration," in Proceedings of the 29th Annual Conference on Explosives and Blasting Technique, 2003.
[11] M. Saadat, A. Hasanzade, and M. Khandelwal, "Differential evolution algorithm for predicting blast induced ground vibrations," International Journal of Rock Mechanics and Mining Sciences, vol. 77, pp. 97-104, 2015.

[12] W. B. Gu, Z. X. Wang, J. H. Chen, J. Q. Liu, M. Lu, and H. M. Xu, "Influence of charge structure on the energy transfer of blasting vibration and explosive effect," Journal of Vibration and Shock, vol. 35, no. 2, pp. 207-211, 2016.

[13] Q. Liang, Y. An, L. Zhao, D. Li, and L. Yan, "Comparative study on calculation methods of blasting vibration velocity," Rock Mechanics and Rock Engineering, vol. 44, no. 1, pp. 93-101, 2011.

[14] H. T. LI and D. Q. SHU, "Influential factors analysis of blasting vibration attenuation law," Engineering Journal of Wuhan University, vol. 38, no. 1, pp. 79-82, 2005.

[15] Z. X. YAN, L. YAN, and P. JIANG, "Prediction methods for blasting-induced ground vibration velocity," Journal of Vibration and Shock, vol. 29, no. 5, pp. 179-183, 2010.

[16] F. Marrara and P. Suhadolc, "Site amplifications in the city of Benevento (Italy): Comparison of observed and estimated ground motion from explosive sources," Journal of Seismology, vol. 2, no. 2, pp. 125-143, 1998.

[17] H. Tang and H.-B. Li, "Study of blasting vibration formula of reflecting amplification effect on elevation," Rock and Soil Mechanics, vol. 32, no. 3, pp. 820-824, 2011.

[18] N. Jiang, C. B. Zhou, W. Ping, X. Xu, and S. W. Lu, "Altitude effect of blasting vibration velocity in rock slopes," Journal of Central South University (Science and Technology), vol. 45, no. 1, pp. 237-243, 2014.

[19] M. Chen, W. Lu, P. Li, M. Liu, C. Zhou, and G. Zhao, "Elevation amplification effect of blasting vibration velocity in rock slope," Chinese Journal of Rock Mechanics and Engineering, vol. 30, no. 11, pp. 2189-2195, 2011 (Chinese).

[20] Y. X. Peng, L. Wu, Y. Su, H. Y. Li, and C. J. Li, "Fitting models of underwater blasting vibration attenuation considering effects of elevation," Journal of Vibration and Shock, vol. 35, no. 13, pp. 173-178, 2016.

[21] T. N. Singh and V. Singh, "An intelligent approach to prediction and control ground vibration in mines," Geotechnical and Geological Engineering, vol. 23, no. 3, pp. 249-262, 2005.

[22] M. Hajihassani, D. Jahed Armaghani, M. Monjezi, E. T. Mohamad, and A. Marto, "Blast-induced air and ground vibration prediction: a particle swarm optimization-based artificial neural network approach," Environmental Earth Sciences, vol. 74, no. 4, pp. 2799-2817, 2015.

[23] M. Monjezi, M. Hasanipanah, and M. Khandelwal, "Evaluation and prediction of blast-induced ground vibration at Shur River Dam, Iran, by artificial neural network," Neural Computing and Applications, vol. 22, no. 7-8, pp. 1637-1643, 2013.

[24] Y.-Q. Liu, H.-B. Li, Q.-T. Pei, and W. Zhang, "Prediction of peak particle velocity induced by underwater blasting based on the combination of grey relational analysis and genetic neural network," Rock and Soil Mechanics, vol. 34, no. 1, pp. 259-264, 2013.

[25] Y. Q. Li and S. Z. Ma, Explosion Mechanics, Science Press, Beijing, China, 1992.

[26] H. H. Tan, J. Z. Sun, and S. W. Qi, "Study on the attenuation of dynamic compaction vibration by heavy tampers," Geotechnical Investigation Surveying, vol. 5, pp. 11-14, 2001.

[27] J. L. Zhang, MATLAB Excel Quantitative Forecast and Decision, Electronic Industry Press, Beijing, China, 2012. 
[28] Y. F. Zhang, D. P. Yao, Z. Z. Xie, Y. X. Xu, G. M. Li, and Y. Q. Ye, "Analysis of master control factor of blasting seismic effect and discussion on shock absorption measures," Rock and Soil Mechanics, vol. 31, no. 1, pp. 304-308, 2010.

[29] H. B. Chu, H. Y. Ye, X. L. Yang, W. M. Liang, and Y. Q. Yu, "Experiments on propagation of blasting vibration based on damage accumulation," Journal of Vibration and Shock, vol. 35, no. 2, pp. 173-177, 2016.

[30] J. Liu, C. S. Wu, and Q. C. Gao, "A research on predicting structural responses to blasting vibration," Explosive and Shock Waves, vol. 20, no. 4, pp. 333-337, 2000. 


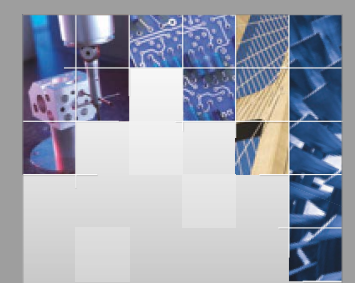

\section{Enfincering}
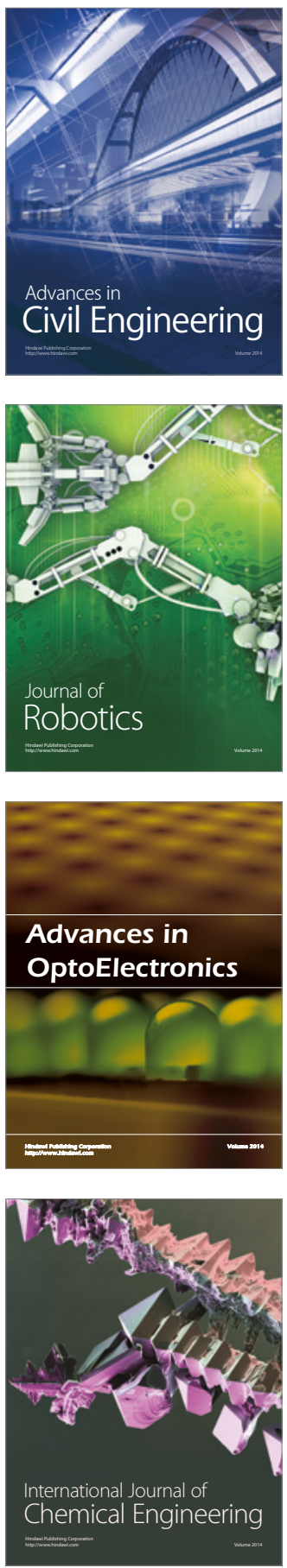

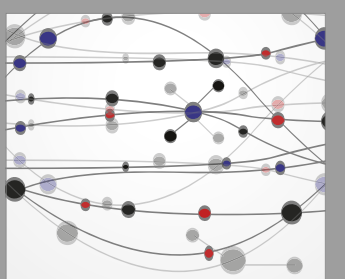

The Scientific World Journal

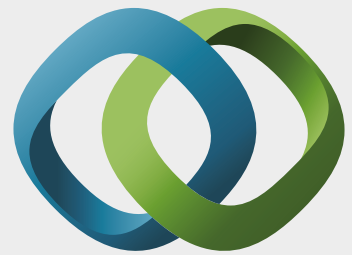

\section{Hindawi}

Submit your manuscripts at

https://www.hindawi.com
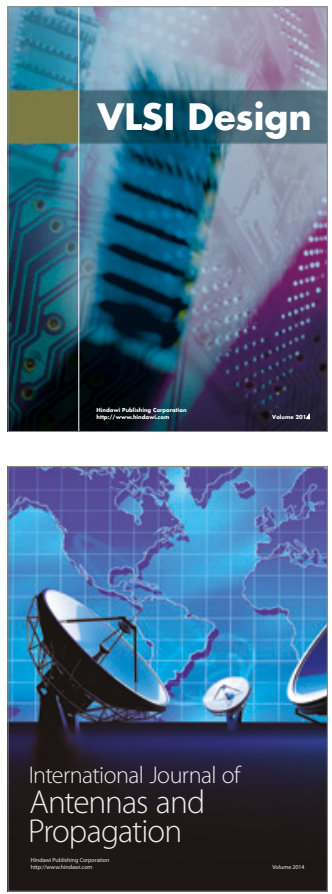

\section{Rotating}

Machinery
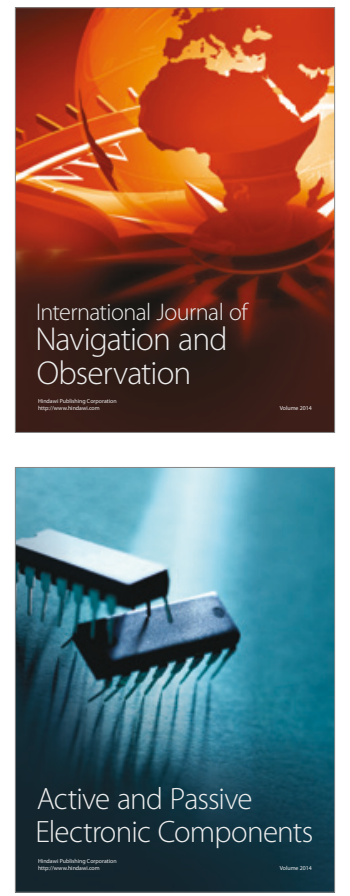
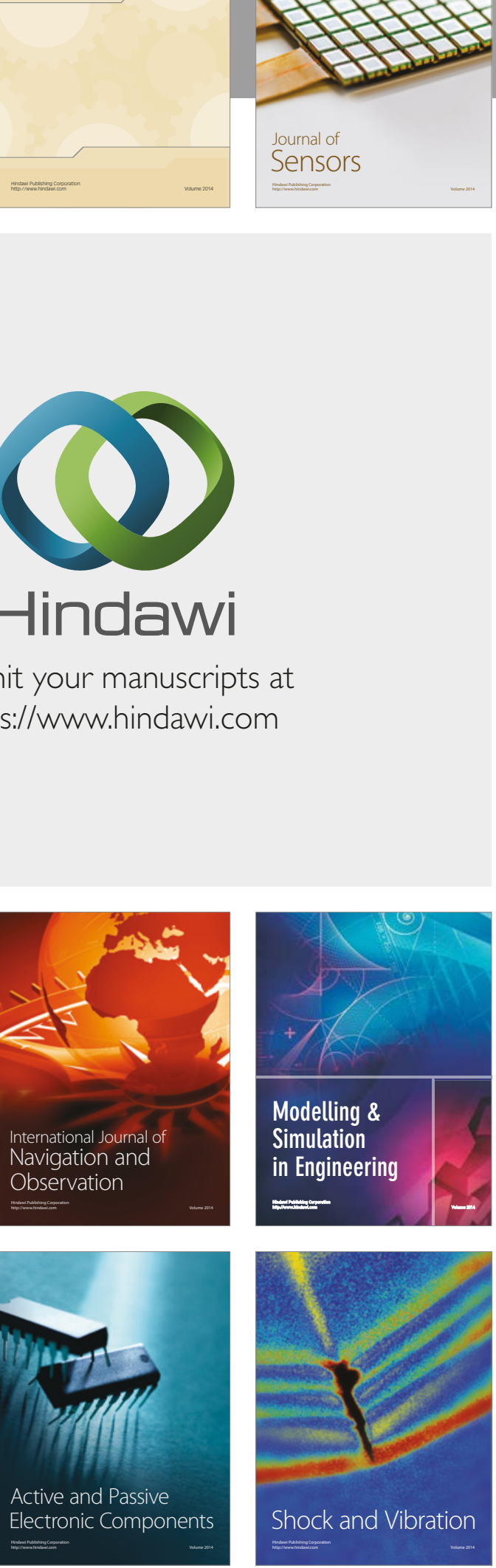
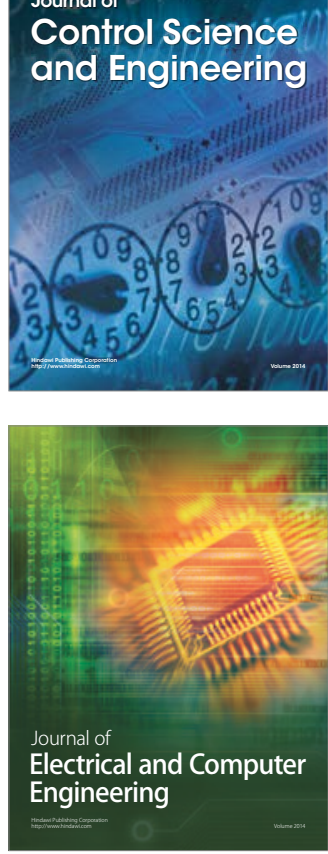

Distributed

Journal of

Control Science

and Engineering
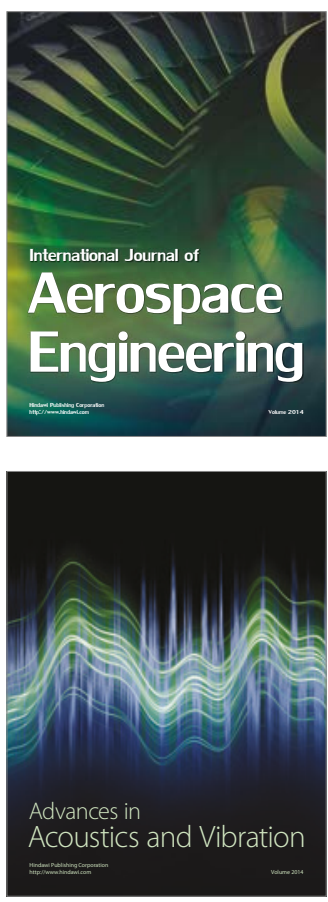

Sensor Networks 